\title{
AUTOMATIC CHANGE DETECTION IN RAPIDEYE DATA USING THE COMBINED MAD AND KERNEL MAF METHODS
}

\author{
Allan A. Nielsen ${ }^{a}$, Antje Hecheltjen ${ }^{b}$, Frank Thonfeld ${ }^{b}$ and Morton J. Canty ${ }^{c}$ \\ ${ }^{a}$ Technical University of Denmark, DTU Space - National Space Institute \\ DK-2800 Kgs. Lyngby, Denmark \\ ${ }^{b}$ University of Bonn, Center for Remote Sensing of Land Surfaces (ZFL) \\ D-53113 Bonn, Germany \\ ${ }^{c}$ Research Center Jülich, Institute of Chemistry and Dynamics of the Geosphere \\ D-52425 Jülich, Germany
}

\section{INTRODUCTION}

Based on orthorectified, bi-temporal 2,000 $\times 2,0005 \mathrm{~m}$ pixel multispectral RapidEye data [1] short-term changes are detected associated with land-use and reclamation in connection with open pit mining in North Rhine-Westphalia, Germany. The changes are found automatically by means of a combination of the iteratively re-weighted MAD method [2], which produces a generalized multivariate difference image, and the kernel MAF method [3]. The IR-MAD method may also be used for automatic radiometric normalization of the data [4]. For the acquisition of ground data for orthorectification and for accuracy assessment, GPS data, supplied by courtesy of RWE Power AG [5], are used.

\section{DATA AND PREPROCESSING}

The study site is located west of Cologne and comprises the Rhenish lignite district, the largest open-cast mining site in Germany. With an annual excavation of 300 million cubic meters (Hambach), 140 million (Garzweiler) and 80 million cubic meters (Inden), respectively, and a total lignite extraction of about 100 million t/a [5] this area is highly dynamic and fast changing. The open-cast mining sites are surrounded predominantly by agricultural areas and some forested areas around the Hambach site.

Two RapidEye images acquired on May 24 and June 1, 2009 were selected to perform the IR-MAD analysis for change detection purposes. The subsets used here cover a region of 2,000×2,000 pixels centered on the Garzweiler site, see Figure 1, where the most accurate GPS data were available for orthorectification. RapidEye is a constellation of five identical satellites operating in the same sun-synchronous orbit. Each of them has five bands which cover the blue (440-510 nm), the green $(520-590 \mathrm{~nm})$, the red $(630-685 \mathrm{~nm})$ the red edge $(690-730 \mathrm{~nm})$, and the near infrared region $(760-850 \mathrm{~nm})$. Ground sampling distance is $6.5 \mathrm{~m}$. Due to its off-nadir capabilities RapidEye is in principle able to achieve daily coverage [6].

The imagery was delivered as level 1B basic product, which means that only radiometric and sensor corrections have been applied [6]. Orthorectification was performed with PCI's [7] Geomatica 10.3 OrthoEngine Module using the rational function

AAN's e-mail is aa@space.dtu.dk, his homepage is http://www.imm.dtu.dk/ aa. 
option $[8,9]$ and a $10 \mathrm{~m}$ digital elevation model. An updated digital elevation model was created for each acquisition time by merging the $10 \mathrm{~m}$ base digital elevation model with the real time digital elevation model that was derived from the excavators GPS ground measurements. DEM resolution was $2 \mathrm{~m}$. To achieve best performance the RapidEye data were converted to $5 \mathrm{~m}$ pixel spacing with cubic convolution interpolation as is done for the RapidEye level 3A ortho standard products [6]. The data are quantized to 16 bit.

Note the clouds in the notheast corner of the image and in the southwest corner of the mine, Figure 1 right.

\section{MAD AND KERNEL MAF TRANSFORMATIONS}

Figure 2 shows the MAD component corresponding to the difference between the highest correlated iterated canonical variates (left) and the so-called $\chi^{2}$ image (right). Gray pixels in the left image are no change pixels, bright and dark pixels are change pixels. The brighter the pixels in the right image the higher is the probability of change.

A kernel formulation of principal component analysis (PCA) [10] may be obtained from Q-mode or dual formulation of the problem combined with the so-called kernel trick [11]. In a similar fashion maximum autocorrelation factor (MAF) analysis $[12,13,3]$ may be kernelized. Figure 3 shows kernel MAF component 1 of the IR-MAD variates based on $\sim 3,000$ training observations (left) and component 6 (right) centered on the mine.

\section{RESULTS AND DISCUSSION}

The IR-MAD components show changes for a large part of the entire subset. Especially phenological changes in the agricultural fields surrounding the open pit are predominant. As opposed to this, kMAF components focus more on changes in the opencast mine (and changes due to the two clouds and their shadows, not visible in the zoom). Ground data were available from bucket-wheel excavators on the extraction side (to the northwest in the open pit) in terms of elevation data for both dates. No ground data were available for changes due to backfill (southeastern part of the open pit) or changes due to mining machines other than the bucket-wheels.

A visual comparison shows that areas detected as change in the kMAF components are related to areas that differ significantly in the two input images. Two observations can be made when comparing the kMAF components with ground data: some areas of extraction were detected perfectly (e.g., the north-most contours in the upper left of Figure 3); others were not detected at all (e.g., the east-most contours in Figure 3). This illustrates the fact that only those changes are detectable which are represented by spectral reflectances in the bands of the sensor (this excludes height information). In the case of the undetected area (the east-most contours), brown coal was extracted leading to an elevation difference of three to seven meters. However, this remained undetected due to the negligible change in reflectance (the pixels being covered by brown coal in both images).

In conclusion the IR-MAD components show changes in the agricultural areas as well as in the mine, and the kMAF components focus on extreme changes in the mine. Due to lack of change in the spectral signal (the change occurs in the height of the surface only) excavation of material (here brown coal) leaving the same material behind is not detected. 

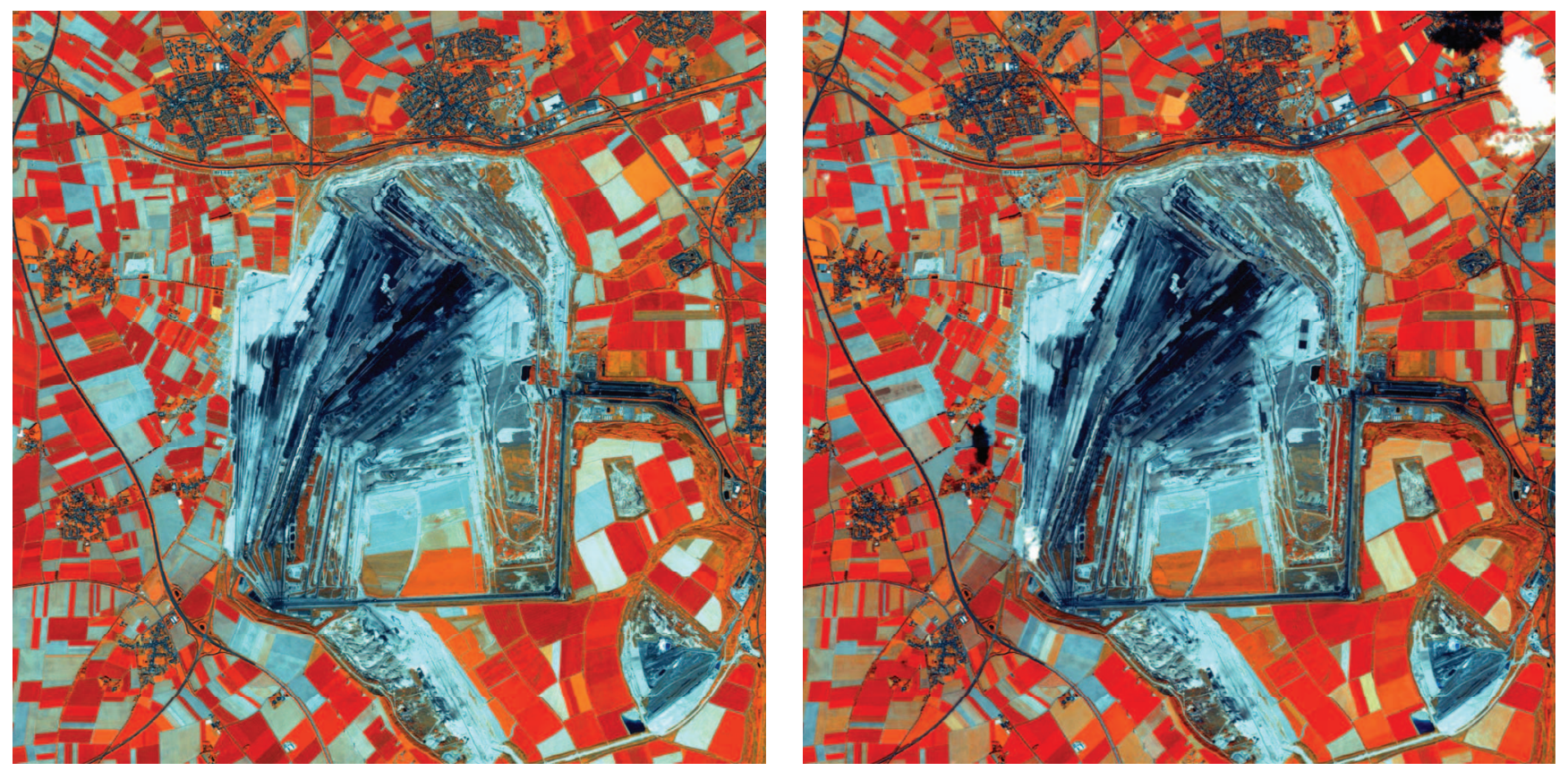

Fig. 1. Orthorectified RapidEye 2,000×2,000 5m pixels subsets, infrared/red edge/red as RGB, 24 May 2009 (left), 1 June 2009 (right). Includes material (c) (2009) RapidEye AG, Germany. All rights reserved.
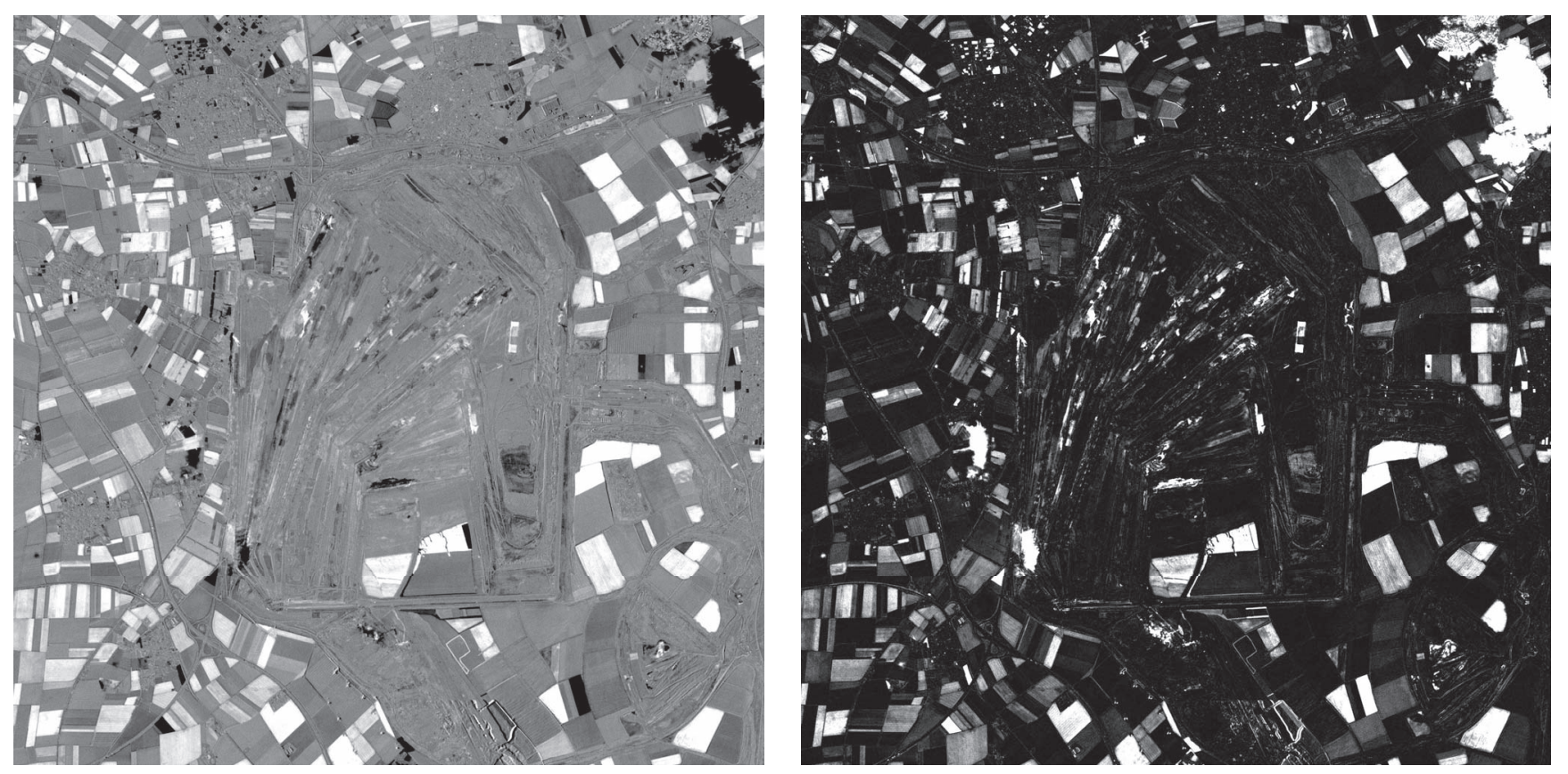

Fig. 2. IR-MAD component 5 (left), $\chi^{2}$ image (right). 

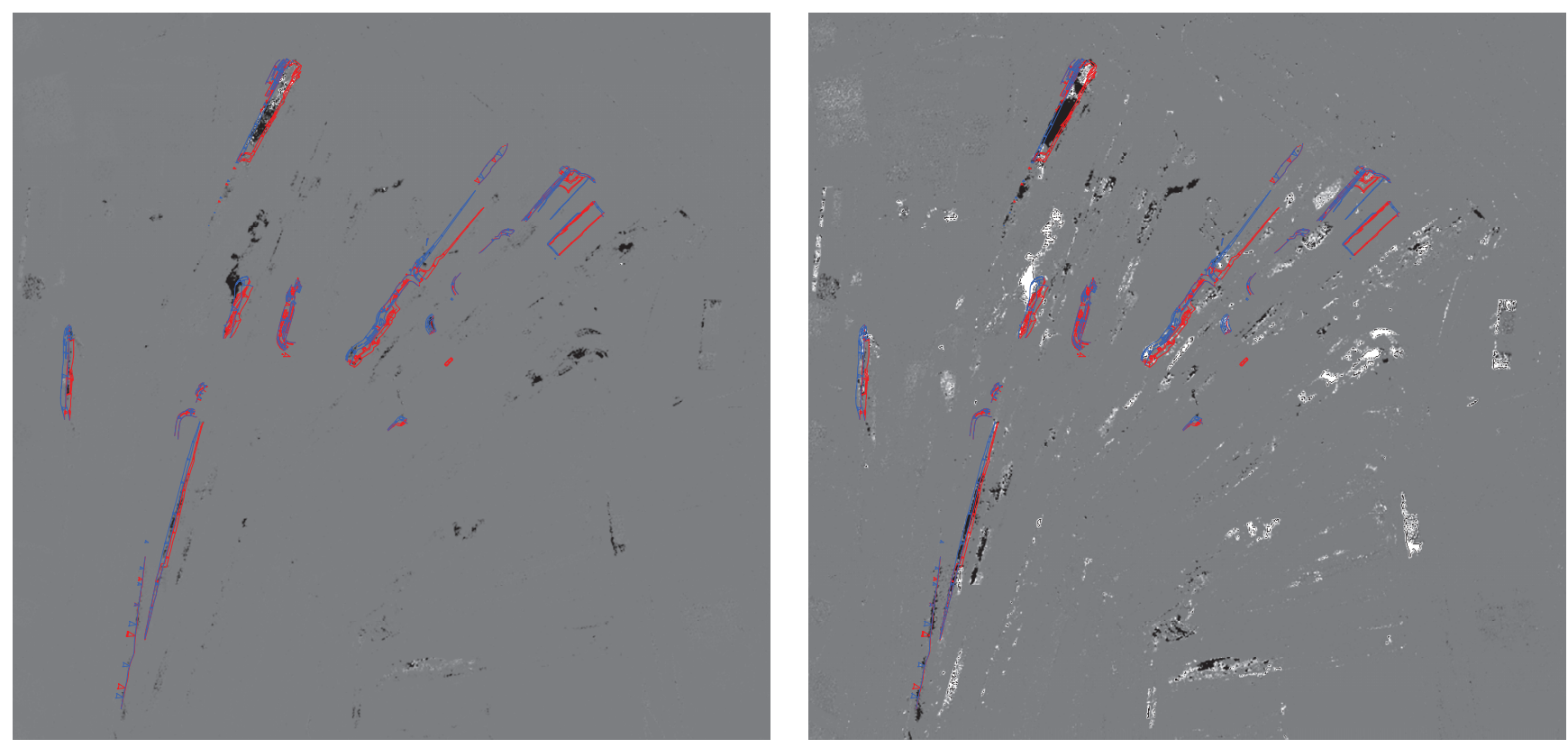

Fig. 3. Zoom of kMAF component 1 (left) and 6 (right) with ground data on bucket-wheel excavation; red: contours as of 24 May 2009, blue: contours as of 01 June 2009.

\section{REFERENCES}

[1] RapidEye AG. Internet: http://www.rapideye.de.

[2] A. A. Nielsen. "The regularized iteratively reweighted MAD method for change detection in multi- and hyperspectral data," IEEE Transactions on Image Processing, 16(2):463-478, 2007. Internet http://www.imm.dtu.dk/pubdb/p.php?4695.

[3] A. A. Nielsen. "Kernel maximum autocorrelation factor and minimum noise fraction transformations," submitted, 2009.

[4] M. J. Canty and A. A. Nielsen. "Automatic radiometric normalization of multitemporal satellite imagery with the iteratively re-weighted MAD transformation," Remote Sensing of Environment, 112(3):1025-1036, 2007. Internet http://www.imm.dtu.dk/pubdb/p.php?5362.

[5] RWE Power AG. 2009. Internet: http://www.rwe.com.

[6] RapidEye AG. "RapidEye Standard Image Product Specifications,” August 2009. Internet: http://www.rapideye.de/upload/ documents/PDF/RE_Product_Specifications_ENG.pdf.

[7] PCI Geomatics. Internet: http://www.pcigeomatics.com.

[8] J. Grodecki and G. Dial. "Block adjustment of high-resolution satellite images described by rational polynomials," Photogrammetric Engineering and Remote Sensing, 49:49-68, 2003.

[9] P. Cheng and J. Sustera. "Using RapidEye data without ground control - automated high-speed high-accuracy," Geomatics, 2009. Internet: http://www.pcigeomatics.com/pdfs/RapidEye.pdf.

[10] H. Hotelling, "Analysis of a complex of statistical variables into principal components," Journal of Educational Psychology, vol. 24, pp. 417-441 and 498-520, 1933.

[11] B. Schölkopf, A. Smola and K.-R. Müller. "Nonlinear component analysis as a kernel eigenvalue problem," Neural Computation, vol. 10, no. 5, pp. 1299-1319, 1998.

[12] P. Switzer and A. A. Green, "Min/max autocorrelation factors for multivariate spatial imagery,” Tech. Rep. 6, Department of Statistics, Stanford University, 1984.

[13] P. Switzer and S. E. Ingebritsen, “Ordering of time-difference data from multispectral imagery," Remote Sensing of Environment, vol. 20, pp. 85-94, 1986. 